\title{
Relationship Between Structure and Antiproliferative Activity of Novel 5-amino-4-cyanopyrazole-1-formaldehydehydrazono Derivatives on HL-60RG Human Leukemia Cells
}

\author{
YUKITOSHI NAGAHARA ${ }^{1}$ and KATSUHIKO NAGAHARA ${ }^{2}$ \\ ${ }^{1}$ Division of Life Science and Engineering, School of Science and Engineering, \\ Tokyo Denki University, Saitama, Japan; \\ ${ }^{2}$ Department of Pharmaceutical Life Sciences, Faculty of Pharmacy, Kitasato University, Tokyo, Japan
}

\begin{abstract}
Background: Pyrazole derivatives have been reported to have potent antimicrobial and anticancer activity. We recently synthesized and determined the effects of analogs, benzamidoxime derivatives, on mammalian cells and discovered that benzamidoximes had an antiproliferative effect. Here we synthesized and determined the anticancer effects of hydrazonopyrazole derivatives on a mammalian cancer cell line. Materials and Methods: We synthesized 12 hydrazonopyrazole derivatives with several constant alkyl chain length or branched chains at the side chain to investigate their anticancer cell activity, using the human myelogenous leukemia cell line $H L$ 60RG. Results: Among all hydrazonopyrazole derivatives we synthesized, the hydrazonopyrazole derivative with a branched chain at the side chain rather than a constant alkyl chain significantly inhibited cell viability. The strongest hydrazonopyrazole derivative, 5-amino-4-cyanopyrazole-1formaldehydehydrazono-3'-pentanal, tended to damage cells dose-dependently. This cell growth attenuation was a result of apoptosis, activating caspase-3 and fragmented DNA. Conclusion: Hydrazonopyrazole derivatives induced apoptosis of HL-60RG leukemia cells.
\end{abstract}

Pyrazole derivatives have been reported to have potent antimicrobial activity (1-3). Pyrazoles also effect mammalian cells and have anti-inflammatory and anticancer activity (4$6)$. These pyrazole derivatives antibiotics have also been reported to possess a broad spectrum of biological activities, not only in microorganisms, but also mammalian cells.

Correspondence to: Yukitoshi Nagahara, Ph.D., Division of Life Science and Engineering, School of Science and Engineering, Tokyo Denki University, Hatoyama, Hiki-gun, Saitama, 350-0394, Japan. Tel: +81 492965949, Fax: +81 492965162, email: yuki@mail.dendai.ac.jp

Key Words: Hydrazonopyrazole, cancer, apoptosis, HL-60RG.
Moreover, it was revealed that pyrazole derivatives induce the apoptosis of mammalian cancer cells $(4,7,8)$.

Many chemicals have been developed to attack cancer cells. For example, the anticancer effect of some chemicals is to attack DNA, inhibit microtubule function, or block metabolism. However, most drugs induce multidrug resistance in cancer cells (9-12), and the development of new classes of anticancer drugs is, thus, necessary. The modes of action of such novel synthesized drugs should also be determined for a better understanding of the component chemicals and for more effective uses in cancer treatments $(13,14)$.

Many chemical anticancer drugs induce apoptosis (15). During apoptosis, mainly caspases, which specifically activate proteases, are involved in processing apoptosis. Caspases are classified as "initiator" caspases and "effector" caspases. The activity of initiator caspases (caspase- 8 and caspase-9) is provoked by various apoptotic stimuli, e.g., mitochondria damage, UV, and environmental stress (16). Once initiator caspases are activated, they in turn activate the effector caspases (caspase-3, -6, and -7) to execute apoptosis by means of chromatin DNA fragmentation, morphological changes, and cell volume loss.

A caspase inhibitor blocks the above phenomena. However, recent studies revealed that apoptotic cell death is not only caspase-dependent; there is also a caspaseindependent pathway. It was reported that pyrazoles also perturb mitochondria directly or indirectly during apoptosis $(17,18)$.

We recently synthesized and determined the effect of analogs, i.e., benzamidoxime derivatives, on mammalian cells, and discovered that the benzamidoximes had an antiproliferative effect (6). In the present study, we determined the effects of hydrazonopyrazole derivatives on a mammalian leukemia cell line, HL-60RG. We synthesized 12 1-formaldehydehydrazonopyrazole derivatives (19) with a several-constant-alkyl-chain length or branched chains at the side chain, and we studied their anticancer cell effects. 


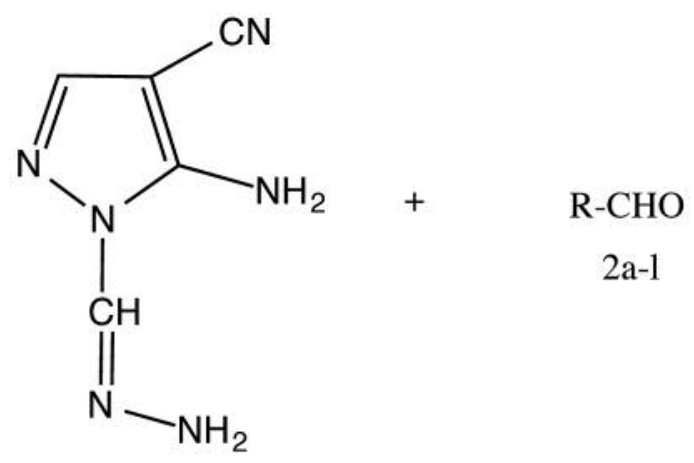

1

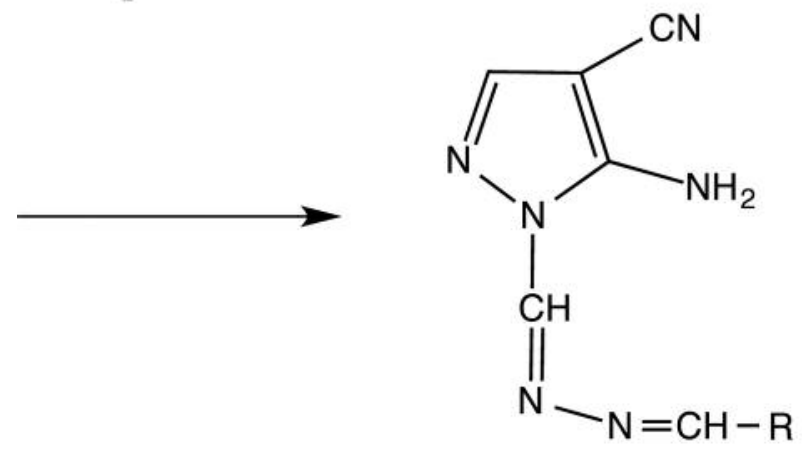

$3 a-1$

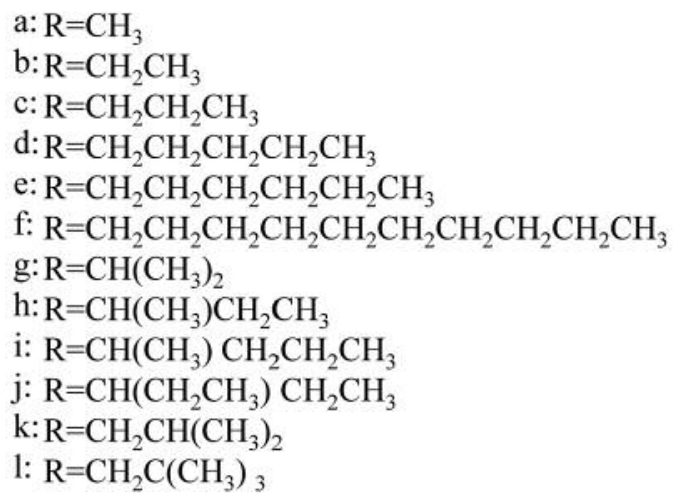

Figure 1. Chemical structures of the hydrazonopyrazole derivatives.

\section{Materials and Methods}

Cells. The human myelogenous leukemia cell line HL-60RG was provided by Human Science Resources Bank (Osaka, Japan).

Reagents. The reaction of 5-amino-4-cyano-1-hydrazinomethyl-pyrazole (1) with an equivalent amount of alkylaldehyde (2a-1) afforded 5-amino4-cyanopyrazole-1-formaldehydehydrazono derivatives (3a-l), as shown in Figure 1.
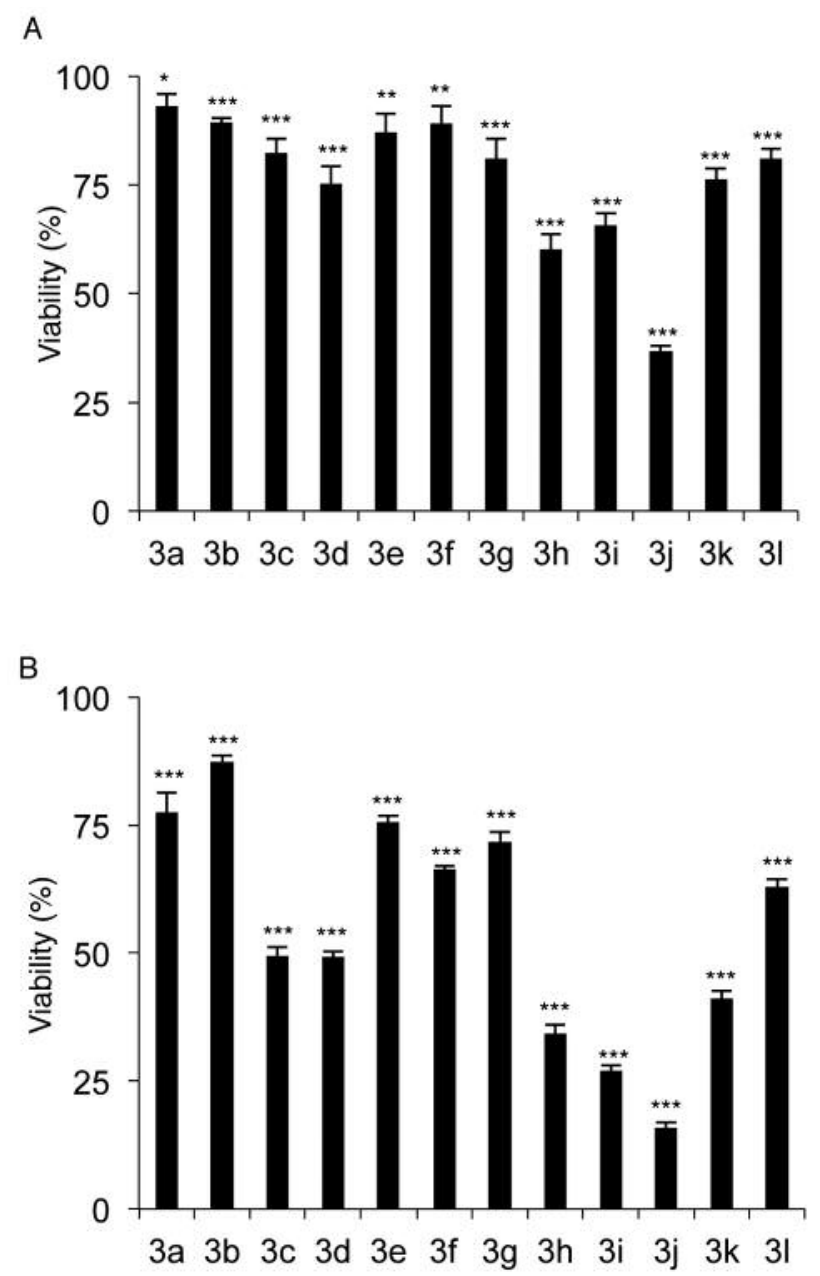

Figure 2. Hydrazonopyrazole derivatives induced damage in HL-60RG cells. HL-60RG cells were incubated with $100 \mu \mathrm{M}$ of hydrazonopyrazole derivatives for $24 h$ (A) or $48 h$ (B). Cell viability was estimated by MTT assay. The data are presented as a comparison to the untreated control. Each bar denotes the $S D(n=4) .{ }^{*} p<0.05, * * p<0.01$, and $* * * p<0.001$ compared to the untreated control groups.

Cell culturing. The cells were cultured in RPMI-1640 medium supplemented with $10 \%$ fetal bovine serum and $75 \mathrm{mg} / \mathrm{l} \mathrm{kanamycin}$ sulfate, and maintained at $37^{\circ} \mathrm{C}$ in a humidified chamber under an atmosphere of $95 \%$ air and $5 \% \mathrm{CO}_{2}$.

Cell viability assay. The cells were incubated in 96-well plates at $37^{\circ} \mathrm{C}$ with test agents for $23 \mathrm{~h}$ or $47 \mathrm{~h}$. Then, $10 \mu \mathrm{l}$ of $5 \mathrm{mg} / \mathrm{ml} \mathrm{3-}$ (4,5-dimethylthiazol-2-yl)-2,5-diphenyl tetrazolium bromide (MTT; Wako, Osaka, Japan) was added to each well, and the plates were incubated at $37^{\circ} \mathrm{C}$ for $1 \mathrm{~h}$. The media were discarded, and $100 \mu \mathrm{l}$ of dimethyl sulfoxide was added to dissolve MTT formazan. The absorbance of each well was measured using a microplate reader (Awareness Technology, Palm City, FL, USA) at $570 \mathrm{~nm}$. The absorbance of the culture wells without test agents was set as $100 \%$. 


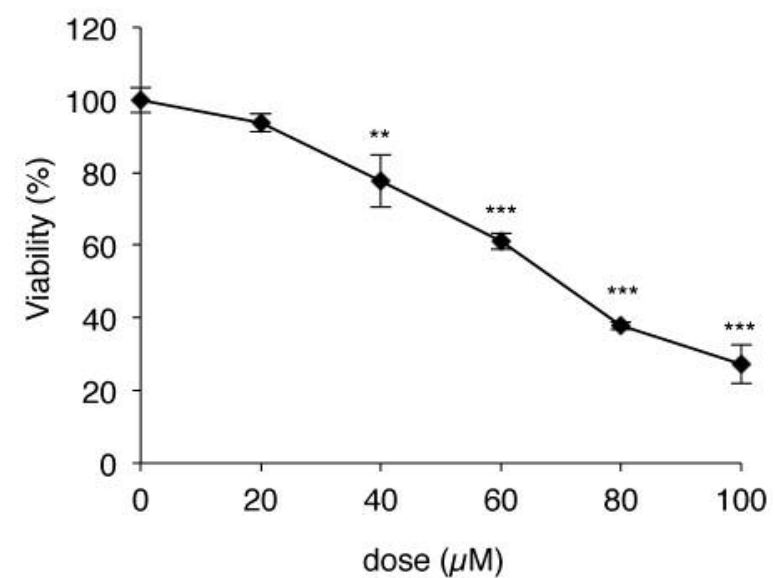

Figure 3. 3j induced dose-dependent cell damage in HL-60RG cells. HL-60RG cells were incubated with the indicated doses of hydrazonopyrazole derivatives for $24 \mathrm{~h}$. Cell viability was estimated by MTT assay. The data are presented as a comparison to the untreated control. Each bar denotes the $S D(n=4) . * * p<0.01$ and $* * * p<0.001$ compared to the untreated control groups.

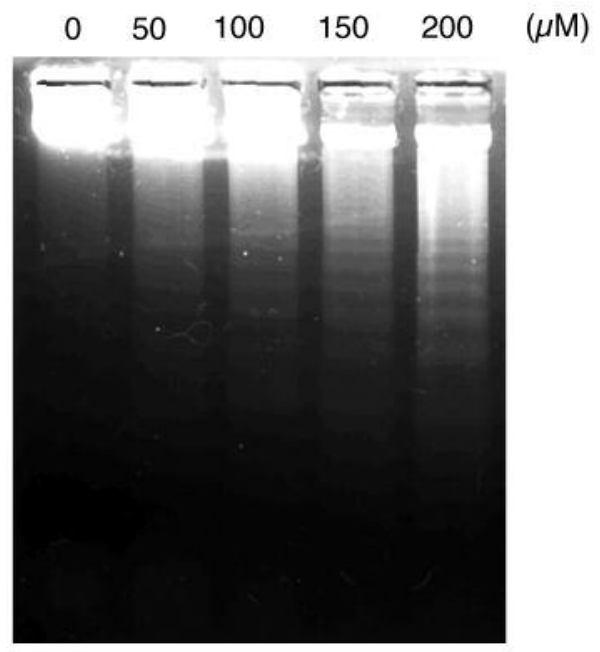

Figure 4. 3j fragmented genomic DNA. HL-60RG cells were incubated with the indicated doses of $\mathbf{3 j}$ for $24 \mathrm{~h}$. The cells were then lysed and DNA was prepared. DNA fragmentation was analyzed by agarose gel electrophoresis. Data are representative of three independent experiments.
Agarose gel electrophoresis. Apoptosis was determined by DNA fragmentation, which was assessed by agarose gel electrophoresis. Cells $\left(1 \times 10^{6}\right)$ were rinsed once with $10 \mathrm{mM}$ Tris- $\mathrm{HCl}$ buffer, $\mathrm{pH} 8.7$, containing $3 \mathrm{mM} \mathrm{MgCl} 2$ and $2 \mathrm{mM} 2$-mercaptoethanol and were dissolved in $50 \mathrm{mM}$ Tris- $\mathrm{HCl}$ buffer, $\mathrm{pH} 7.8$, containing $10 \mathrm{mM}$ EDTA, $0.5 \%$ sodium lauryl sarcocinate, and $1 \mathrm{mg} / \mathrm{ml}$ proteinase $\mathrm{K}$. After incubation at $50^{\circ} \mathrm{C}$ for $30 \mathrm{~min}$, RNase A was added at a concentration of $0.5 \mathrm{mg} / \mathrm{ml}$ and further incubated at $50^{\circ} \mathrm{C}$ for $15 \mathrm{~min}$. Lysates were mixed with an equal volume of loading buffer containing TBE buffer (89 mM Tris, pH 8.4, $2.5 \mathrm{mM}$ EDTA, $89 \mathrm{mM}$ boric acid), $20 \%$ glycerol, and $0.01 \%$ bromophenol blue. Samples were electrophoresed on $1.8 \%$ agarose gels in TBE containing 0.5 $\mathrm{mg} / \mathrm{ml}$ ethidium bromide.

Western blotting. Cells were washed with phosphate-buffered saline (PBS) and placed on ice for $20 \mathrm{~min}$ in lysis buffer: $50 \mathrm{mM}$ HEPES$\mathrm{NaOH}, 10 \%$ glycerol, $150 \mathrm{mM} \mathrm{NaCl}, 1 \%$ Triton X-100, $1 \mathrm{mM}$ EGTA, $1.5 \mathrm{mM} \mathrm{MgCl} 2,1 \%$ proteinase inhibitor cocktail (Sigma, St. Louis, MO), $\mathrm{pH}$ 7.5, 0.1 mM sodium orthovanadate. Cell lysates were centrifuged at $4^{\circ} \mathrm{C}$ for $15 \mathrm{~min}$ at $13,000 \times \mathrm{g}$. The protein concentrations of the supernatant were determined using a Bicinchoninic Acid protein assay (Thermo Scientific, Waltham, MA, USA). Cell lysates $(30 \mu \mathrm{g})$ were mixed in the same volume of sodium dodecyl sulfate (SDS) sample buffer (4\% SDS, $125 \mathrm{mM}$ Tris, pH 6.8, $10 \%$ glycerol, $0.02 \mathrm{mg} / \mathrm{ml}$ bromophenol blue, $10 \% 2$ mercaptoethanol) and heated at $100^{\circ} \mathrm{C}$ for $3 \mathrm{~min}$. Proteins were separated by $15 \%$ polyacrylamide gel SDS-electrophoresis and electrically transferred to a polyvinylidene difluoride membrane (Bio-Rad Laboratories, Hercules, CA). After the membrane was blocked with use of $3 \%$ skimmed milk, caspase- 3 and $\beta$-actin were immunodetected using specific antibodies (Santa Cruz Biotechnology, Dallas, TX, USA). Thereafter, horseradish peroxidase-conjugated anti-rabbit IgG (Cell Signaling Technology,
Danvers, MA) was applied as the second antibody, and positive bands were detected by enhanced chemiluminescence (Thermo Scientific). Visualization was done with an Image Quant LAS-4000 (GE Healthcare, Buckinghamshire, UK).

Statistical analysis. All statistical analyses were performed using Student's $t$-test. Significance was established at the $p<0.05$ level.

\section{Results and Discussion}

Hydrazonopyrazole derivatives induced the cell damage of leukemia cells. We synthesized 12 hydrazonopyrazole derivatives which were then used throughout this study (Figure 1). Compounds 3a-f were hydrazonopyrazoles with a straight chain at the side chain, and compounds $\mathbf{3 g - 1}$ were hydrazonopyrazoles with a branched chain at the side chain. To estimate the potency of hydrazonopyrazole derivatives in mammalian cells, we performed an MTT assay to determine the extent of cell injury in HL-60RG leukemia cells. Synthesized hydrazonopyrazole derivatives were incubated with $100 \mu \mathrm{M}$ for $24 \mathrm{~h}$ on HL-60RG cells. Among our newlysynthesized compounds, the hydrazonopyrazole with a branched chain at the side chain, that is, 5-amino-4cyanopyrazole-1-formaldehydehydrazono-3'-pentanal, $\mathbf{3 j}$, was the most effective compound (Figure 2A).

Moreover, the longer treatment time $(48 \mathrm{~h})$ of the compounds resulted in a more damaging effect on HL-60RG cells, which suggests that hydrazonopyrazoles with a branched chain at the side chain compounds tended to induce cell damage compared to the compounds with a straight chain 
A

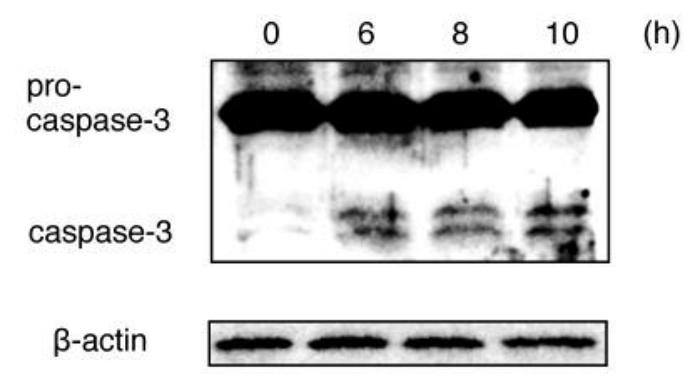

B

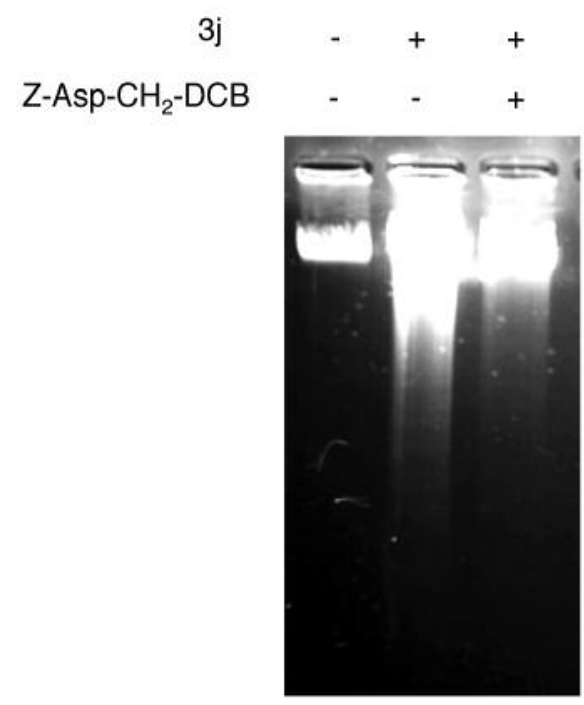

Figure 5. Caspase-dependent apoptosis induced by $3 \mathrm{j}$ in HL-60RG cells. A: HL-60RG cells were incubated with $100 \mu \mathrm{M} 3 \mathrm{j}$ for the indicated times. The cells were then lysed, and caspase-3 was detected by western blotting. Data are representative of three independent experiments. $B$ : $H L-60 R G$ cells were incubated with or without $40 \mu \mathrm{M} Z-A s p-C H_{2}-D C B$, then $100 \mu \mathrm{M} 3 \mathrm{j}$ for $24 \mathrm{~h}$. The cells were then lysed and DNA was prepared. DNA fragmentation was analyzed by agarose gel electrophoresis. Data are representative of three independent experiments.

at the side chain, in a time-dependent manner (Figure 2B). Moreover, our newly-synthesized compounds with an alkyl chain with 4-6 carbon atoms had a strong cell-damaging effect, and the compounds with shorter or longer than 4-6 carbon atoms had less toxicity. These results suggest that a bulky substituent, not the electrical charge, is important for cell damage and that cell membrane permeability would affect the compounds' toxicity because too long a straight chain may decrease the membrane permeability.

In order to determine the half-maximal inhibitory concentration $\left(\mathrm{IC}_{50}\right)$ of the most effective compound, $\mathbf{3 j}$, we treated HL-60RG cells with $0-100 \mu \mathrm{M} \mathbf{3 j}$ for $24 \mathrm{~h}$. The estimated $\mathrm{IC}_{50}$ dose of $3 \mathrm{j}$ was approximately $73 \mu \mathrm{M}$ (Figure 3). Taken together, these results indicate that hydrazonopyrazole derivatives induce cell damage in HL60RG cells and that the branched chain at the side chain increases the derivatives' potency.

Hydrazonopyrazole derivatives induced apoptosis of $H L$ $60 R G$ cells with caspase activation. With the above findings we further examined how this cell damage effect occurred in response to hydrazonopyrazole treatment, using the drugsusceptible cell line HL-60RG. First, we assayed DNA fragmentation, which is a hallmark of apoptosis. As shown in Figure 4, doses over $100 \mu \mathrm{M}$ of $\mathbf{3} \mathbf{j}$ fragmented DNA in a 24-h treatment. Moreover, one of the effector caspases, i.e., caspase- 3 was detected by western blotting. As shown is Figure 5A, pro-caspase- 3 was decreased and cleaved to an active form by $100 \mu \mathrm{M} \mathrm{3 \mathbf {j }}$ in a $<6-\mathrm{h}$ treatment, suggesting that $\mathbf{3} \mathbf{j}$ induced apoptosis with the activation of caspase-3. Moreover, the pan-caspase inhibitor Z-Asp- $\mathrm{CH}_{2}$-DCB was administered prior to the incubation with $100 \mu \mathrm{M} 3 \mathbf{j}$. The ZAsp- $\mathrm{CH}_{2}$-DCB treatment blocked DNA fragmentation, suggesting that the $\mathbf{3} \mathbf{j}$-induced apoptosis was caspasedependent. Many chemical anticancer drugs induce apoptosis by provoking mitochondria (15). Damaged mitochondria release cytochrome $c$. The released cytochrome $c$ then binds to Apaf-1 and activates one of the initiator caspase, caspase-9, with formation of apoptosome. Activated caspase-9 further activates effector caspase, caspase-3. Caspase-3 then execute apoptotic cell death. Compound $\mathbf{3 j}$ might induce apoptosis by above-mentioned pathway. Further studies are warranted to investigate the precise mechanism of apoptosis induction by $\mathbf{3 j}$.

Overall, our findings indicate that the novel synthesized compounds are promising drugs that may be used to damage cancer cells at very low treatment doses.

\section{Acknowledgements}

The Authors are grateful to Mr. Wataru Ueda, Mr. Naoya Shimura, and Ms. Yuna Ueda for their technical assistance.

\section{References}

1 Mabkhot YN, Kaal NA, Alterary S, Al-Showiman SS, Barakat A, Ghabbour HA and Frey W: Synthesis, in vitro antibacterial, antifungal, and molecular modeling of potent anti-microbial agents with a combined pyrazole and thiophene pharmacophore. Molecules 20: 8712-8729, 2015.

2 Bekhit AA, Hymete A, El-Din ABA, Damtew A and AboulEnein HY: Pyrazoles as promising scaffold for the synthesis of anti-inflammatory and/or antimicrobial agent: a review. Mini Rev Med Chem 10: 1014-1033, 2010.

3 Trape AP and Gonzalez-Angulo AM: Breast cancer and metastasis: on the way toward individualized therapy. Cancer Genomics Proteomics 9: 297-310, 2012. 
4 Bekhit AA and Abdel-Aziem T: Design, synthesis and biological evaluation of some pyrazole derivatives as anti-inflammatoryantimicrobial agents. Bioorg Med Chem 12: 1935-1945, 2004.

5 Bekhit AA, Fahmy HT, Rostom SA and El-Din ABA: Synthesis and biological evaluation of some thiazolylpyrazole derivatives as dual anti-inflammatory antimicrobial agents. Eur J Med Chem 45: 6027-6038, 2010

6 Nagahara $\mathrm{Y}$ and Nagahara K: N-(2-amino-5-chlorobenzoyl) benzamidoxime derivatives inhibit human leukemia cell growth. Anticancer Res 34: 6521-6526, 2014.

7 Nitulescu GM, Draghici C, Olaru OT, Matei L, Ioana A, Dragu LD and Bleotu C: Synthesis and apoptotic activity of new pyrazole derivatives in cancer cell lines. Bioorg Med Chem 23: 5799-5808, 2015.

8 Toton E, Ignatowicz E, Bernard MK, Kujawski J and Rybczynska M: Evaluation of apoptotic activity of new condensed pyrazole derivatives. J Physiol Pharmacol 64: 115-123, 2013.

9 Stavrovskaya AA: Cellular mechanisms of multidrug resistance of tumor cells. Biochemistry (Mosc) 65: 95-106, 2000.

10 Baguley BC: Multiple drug resistance mechanisms in cancer. Mol Biotechnol 46: 308-316, 2010.

11 Daniel C, Bell C, Burton C, Harguindey S, Reshkin SJ and Rauch C: The role of proton dynamics in the development and maintenance of multidrug resistance in cancer. Biochim Biophys Acta 1832: 606-617, 2013.

12 Molnar J, Engi H, Mandi Y, Somlai C, Penke B, Szabo A and Orosz A: Effects of nontoxic heat shock protein 90 inhibitor peptide derivatives on reversal of MDR of tumor cells. In Vivo 21: 429-433, 2007.
13 Ozben T: Mechanisms and strategies to overcome multiple drug resistance in cancer. FEBS Lett 580: 2903-2909, 2006.

14 Cruz IN, Coley HM, Kramer HB, Madhuri TK, Safuwan NA, Angelino AR and Yang M: Proteomics analysis of ovarian cancer cell lines and tissues reveals drug resistance-associated proteins. Cancer Genomics Proteomics 14: 35-51, 2017.

15 Cain K: Chemical-induced apoptosis: formation of the Apaf-1 apoptosome. Drug Metab Rev 35: 337-363, 2003.

16 Kuribayashi K, Mayes PA and El-Deiry WS: What are caspases 3 and 7 doing upstream of the mitochondria? Cancer Biol Ther 5: 763-765, 2006.

17 Giansanti V, Camboni T, Piscitelli F, Prosperi E, La Regina G, Lazze MC, Santin G, Silvestri R and Scovassi AI: Study of the effects of a new pyrazolecarboxamide: changes in mitochondria and induction of apoptosis. Int J Biochem Cell Biol 41: 18901898, 2009.

18 Perchellet EM, Ward MM, Skaltsounis AL, Kostakis IK, Pouli N, Marakos P and Perchellet JP: Antiproliferative and proapoptotic activities of pyranoxanthenones, pyranothioxanthenones and their pyrazole-fused derivatives in HL-60 cells. Anticancer Res 26: 2791-2804, 2006.

19 Takagi K, Nagahara K, and Ueda T: Sur la formation d'un derive pyrazolique original a partir d'hydrazine et d'ethoxymethylene malononitrile. Chem Pharm Bull 18: 2353-2356, 1970.

Received June 12, 2017

Revised June 27, 2017

Accepted June 28, 2017 